\title{
Using Social Media in Building and Managing Corporate Identity: Study on Real Estate Companies in the Kingdom of Bahrain
}

\author{
Kamel Gharbi \\ Amina al-Tamimi \\ Department of Communication, Tourism \& Fine Arts \\ University of Bahrain, Kingdom of Bahrain
}

\section{Keywords}

Bahrain real estate companies, corporate identity, corporate image, communication, managing corporate identity, Social media.

\begin{abstract}
Purpose of the Research: This study aims to understand the use of social media in building and managing corporate identity in Bahraini real estate companies. It will be based on the qualitative approach and aim to reach a deeper understanding of the perceptions adopted by Bahraini real estate companies in developing identity-building strategies and management methods.

Design/Methodology: The study will focus on a sample of Bahraini real estate companies. It will also rely on semi-structured interviews as a data collection tool with managers, decision-makers or public relations managers of these companies.

Results/Findings: Most of the real estate companies (8 out of 11) agreed that traditional media, such as newspapers, radio, and television, were unable to promote the company's services because of its narrow scope. New media should be used to target wider audiences.

Practical Implications/Conclusion: The authors argue that managers should adapt to the new form of communication and take advantage of the power of consumer chatter in these ways and amplify them to influence other consumers. The interviews revealed that the use of the Internet has changed the behavior of consumers, and the marketing methods of products and services, as it created a new marketing environment in these media.
\end{abstract}

Corresponding author: Kamel Gharbi

Email addresses for the corresponding author: kgharbi@uob.edu.bh

First submission received: $24^{\text {th }}$ October 2019

Revised submission received: $6^{\text {th }}$ December 2019

Accepted: 19 $9^{\text {th }}$ December 2019

\section{Introduction}

With the emergence of social media, individuals can communicate with each other and discuss everything related to a company and its products and services. Thus, the communication between consumers has expanded, facilitating the exchange of information and evaluation of various products and commodities. Therefore, some consider this to be a hybrid element of promotion (Mangold \& Faulds, 2009) because it allows the company to address its customers on the one hand, while allowing customers to communicate with each other on the other. In this sense, social media works like electronic word of mouth (eWOM) Goodrich \& De Mooij, 2014). Therefore, the company loses its full control over the communication process as in the traditional model. Several studies have shown that the consumer is becoming much more confident in opinion leaders among his relatives, friends, co-workers, and others (Kaplan \& Haenlein, 2010; Kotler \& Keller, 2010). This interest has been a catalyst for innovative communication strategies.

Many modern studies (Stuart, 1999; Mangold and Faulds, 2009) agree that modern communication technologies and social media have inevitably changed perceptions and paradigms and have driven small, medium, and large enterprises to review strategies for building and managing their identity through virtual space. Since identity and reputation are fundamental factors of their success and competitiveness (Cornelissen \& Elving, 2003), companies of various sizes and activities seek to optimize 
the use of social media to build their identity and manage their reputation. This study focuses on how social media can be used to effectively build and manage corporate identity in the Kingdom of Bahrain.

\section{Literature review Corporate identity}

The concepts of corporate identity, corporate image and corporate reputation are often confused, and some terms are even used to denote the other. Stuart Albert and David A. Whetten (1985) developed the foundation for the concept of corporate identity. It has also recently been developed in the field of organizational communication studies by Charles Fombrun and Cees Van Riel in their joint book "Fundamentals of Organizational Communication: Best Practices for Effective Reputation Management" (2007) and in Wally Olins "Brand New: The Shape of Brands to Come" (2014). In various literature (Olins 2008, 2014 ; Melewer, 2008 ; Fombrun \& Van Riel, 2007 ; Barnett, Jermier \& Lafferty, 2006), the corporate identity is seen as a set of visual aspects and symbols that distinguish a company from its competitors (such as brand name, logo, advertising symbol, distinctive color, etc.). It is a system of fundamental beliefs and values presented to the company's internal and external audience, through behavior, communication and the symbolic system. (Balmer \& Van Riel, 1997). It is defined by Wally Olins and others as how the organization presents itself and demonstrates its distinctiveness towards stakeholders. According to Melewer (2008), the concept of corporate identity is linked to the intrinsic characteristics of organizations in terms of personality, individuality, excellence, meaning, substance and behavior.

Originally, corporate identity programs target external stakeholders or audiences (such as customers, investors, and the public), but more recently, target groups have been expanded to include employees (e.g. internal stakeholders).

Accordingly, the corporate identity depends on an integrated media strategy that includes both traditional and new media. With the advent of social media, the tools and strategies used to communicate with customers and stakeholders have changed, creating new concepts related to the consumer and its role in the communication process. The consumer is able to produce and disseminate information, data and experiences about the brand, product or services

\section{Social media and marketing}

According to Zarella (2010), social media and marketing are best known in the context of the traditional media model, such as television, newspapers, radio, and magazines. They are one-way, with fixed broadcasting technologies. Web technologies make it easy for anyone to create pages and, more importantly, distribute that content in several types of platforms, such as blogs, tweets, or YouTube and show it to millions for free (Zarella, 2010). Kaplan \& Heanlein defines it as "a group of Internet-based applications that built on the ideological and technological foundations of Web 2.0, and that allow the creation and exchange of user-generated content" (Kaplan \& Heanlein, 2010, p.61).

Since the advent of the second and third generation of the web, social media applications and platforms have been growing and evolving, giving organizations greater opportunities to communicate with the customer. At the same time, it allows customers to communicate and share experiences (Gillin, 2007). Christopher Vollmer and Geoffrey Precourt noted that consumers now have full control over the social media space and have greater access to information and thus media leadership than ever before (Vollmer \& Precourt, 2008).

Most social media experts and scholars emphasized the importance of integrating social media into a comprehensive marketing strategy. It is therefore important for companies to recognize that social media is not just channels for disseminating information about companies. Therefore, it is important that the company make use of social media to serve its goals and objectives (Kaplan, 2015; Doorley \& Garcia, 2011).

\section{Conceptual Framework}

Helen Stuart's model of the corporate identity management process (1999) (Figure 1) is a revision of Russell Abratt's model, which was drafted in 1994 and updated in 1998. Stuart has added corporate culture and the structure of internal and external communications to the model. Employees were also considered with key stakeholder groups because their opinion about the identity of the company is 
particularly important. However, this model did not include social media, which didn't become widespread until the first decade of the 21st-century.

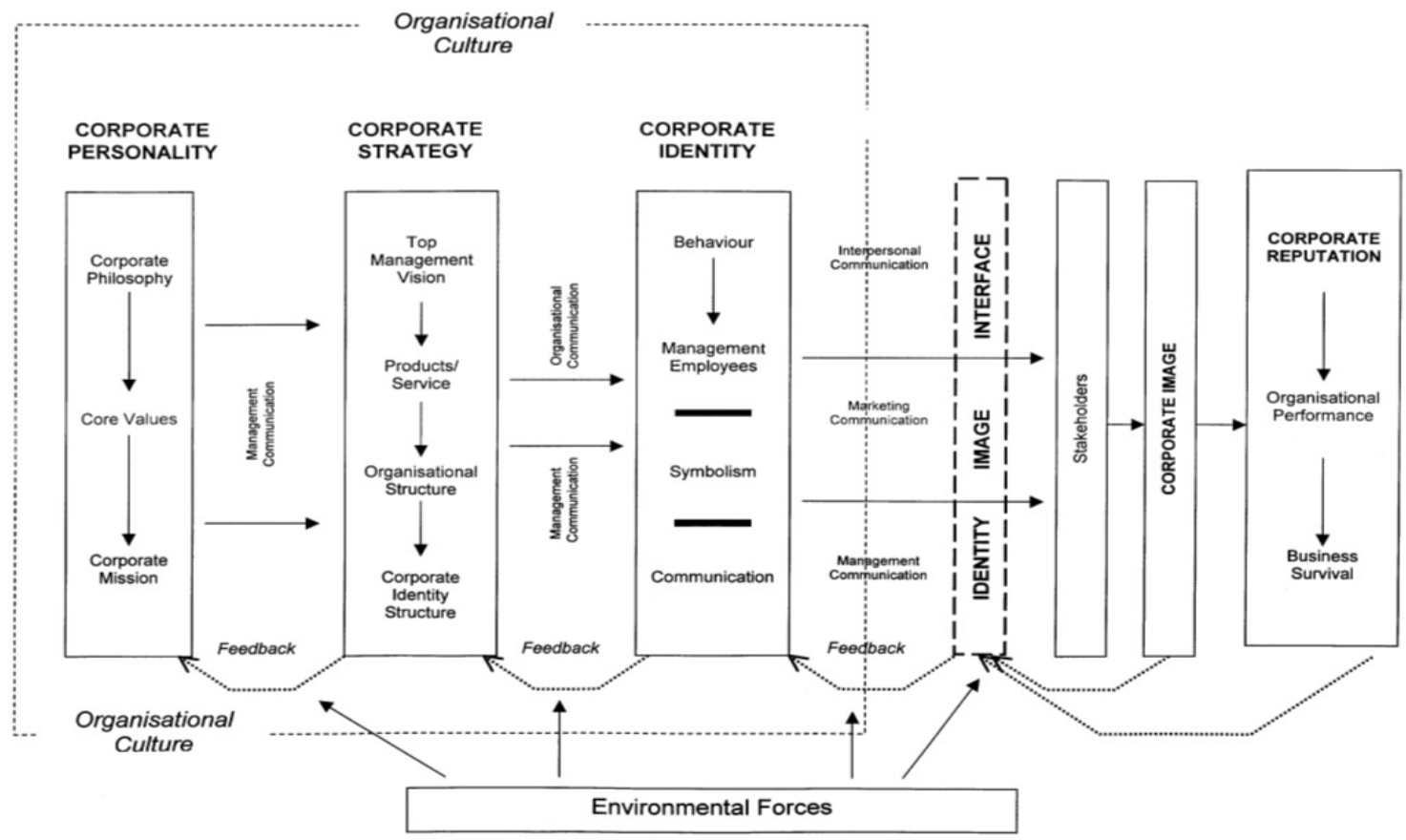

Figure 1. Towards a definitive model of the corporate identity management process (Stuart, 1999, p 206).

This study, therefore, took advantage of a complementary model presented by Glynn Mangold and David J. Faulds) 2009), (Figure 2). This model discusses the impact of social media on consumers, as the individual communicates with other consumers about companies and their products. "In the new communications paradigm, marketing managers should recognize the power and critical nature of discussions being carried on by consumers using social media" (Mangold \& Faulds, 2009, p 360).

Companies have always been in control of the flow of communication with the target audience. However, the emergence of new media has greatly reduced this control. The new changing communication landscape is, therefore, different from the traditional Integrated Marketing Communications (IMC) model, which was characterized by a high level of communication control by the company. Therefore, companies realized the importance of achieving the requirements of this new form of communication by taking customer discussions into account, thereby benefiting from them in developing their marketing strategies.

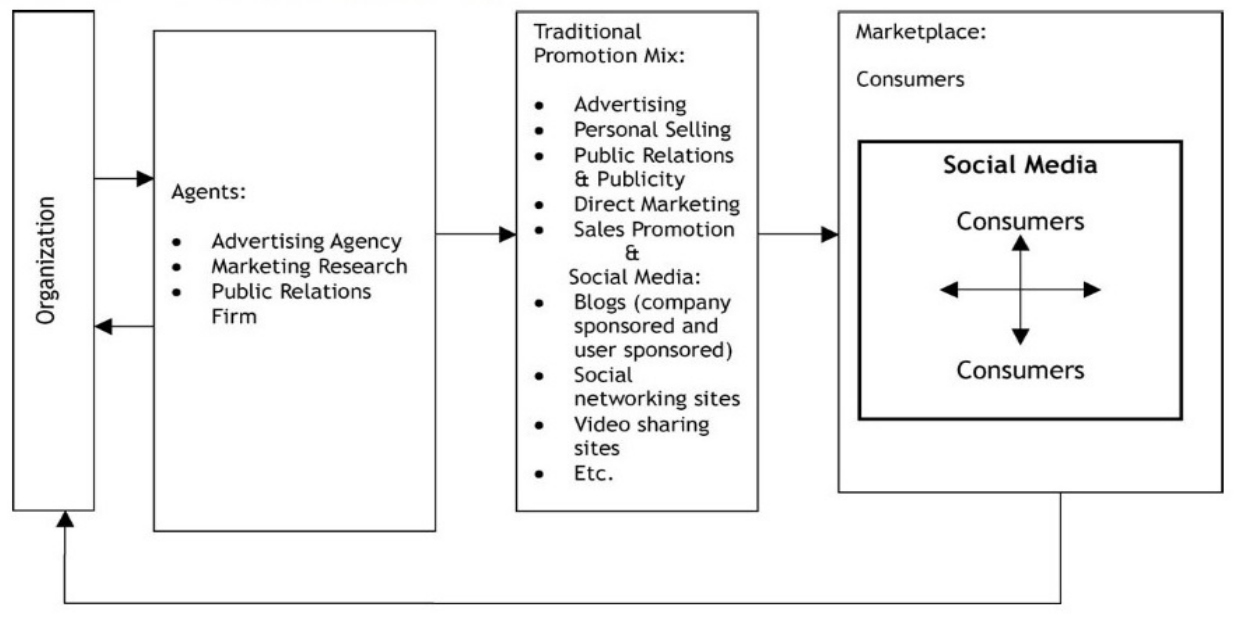

Figure 2. The new communications paradigm (Mangold \&. Faulds, 2009, p 360). 


\section{Research approach and data analysis}

The current research raises the following question: How do real estate companies in the Kingdom of Bahrain use social media to build and manage their corporate identity. To answer this question, the researchers used a qualitative approach and relied on the semi-structured interview tool for data collection. A semi-structured interview helps to get ideas, opinions, representations, and determinants of behavior by asking good questions (Berger, 2011).

Because of the different representations about the role of social media in building and managing corporate identity, this work adopts an interpretive approach. Both Lindlof and Taylor (2011) believe that the interpretive approach presupposes the existence of multiple facts determined by thinking that constantly changes and evolves. The authors also believe that the use of this approach means that the researcher does not care about what should exist but is interested in understanding what already exists. The research society is comprised of real estate companies operating in the Kingdom of Bahrain. The research sample consists of public relations specialists or supervisors of social media content. Since the objective of qualitative studies is to understand phenomena rather than to measure their dimensions and impact within the research community, this research sought to reach a diverse sample to present different perspectives and monitor differences within the studied society. For this purpose, the Purposive Sample or Judgment Sample was selected, which is a sample of participants who are rich in information about the subject studied.

Based on the above, the research sample included 11 real estate companies $(n=11)$ from among the companies operating in the Kingdom of Bahrain (some of these companies are expanding in other markets outside of the Kingdom). Accordingly, 11 semi-structured interviews were conducted with a sample of representatives of real estate companies (public relations specialists or supervisors of social media content) during February and March 2017.

In addition to the general questions, the in-depth interview guide consists of 35 questions, which have been divided into several main areas, including Characteristics of social media, social media communication strategy, Social media and corporate reputation. Interviews and observations were also recorded. In the first stage, the emphasis was placed on the content disseminated by these companies through social media. Then, all interviews proceeded based on the interview guide.

The analysis process went through five stages:

Converting the recorded data into digital files (this process was completed manually because the data is recorded in Arabic and, thus, impossible to be analyzed electronically using any of the available qualitative data analysis software, or tools).

Encoding the interviews; this is to identify the codes (words, sentences or syllables) according to their relationship/relevance/match with the research questions.

Defining the matrices/units of analysis/topics/categories, which is meant to compile codes according to their meanings (or their contribution to the meaning).

Naming and arranging the topics/categories and determining the relationship between them, with a focus on those that reflect the problem under investigation.

Identifying the most frequent subjects/categories in relation to the study questions.

\section{Results}

Based on the matrix of topics identified after coding the data collected by semi-standard interviews, we present a part of this matrix with the most relevant results. Using the media to introduce the company to its customers and marketing its services. All Bahraini real estate companies rely on traditional media (e.g., newspapers, radio, television, and advertising) to reach target audiences. These companies focus primarily on printed publications and advertisements and then on other media. Some companies also use real estate exhibitions, outdoor advertising, and direct marketing (such as relying on brokers) to build a corporate image and draw the public's attention to it.

"Social media accounts for $20-30 \%$ of the business strategy. We still believe in direct marketing (for example, investor visits). We always focus on the written side. We are not able to approach social media at the expense of newspaper advertising. Despite the aesthetics of our website and its interaction, we are not currently able to focus all of our communication activity on it. "(D.L). Most of the real estate companies (8 out of 11) agreed that traditional media, such as newspapers, radio, and television, were 
unable to promote the company's services because of its narrow scope. New media should be used to target wider audiences. Three companies pointed out that the traditional media are sufficient to introduce the company to the target audience and that they do not use new media but might use them in the future.

Companies seek to recruit individuals according to their skills. Therefore, the characteristics of the supervisors of the social media are to be creative in this field and to be able to use the information and communication technology and keep abreast of all developments in this field. This will be reflected in the way the company manages its corporate identity with an excellent team and an electronic content that helps in marketing.

\section{Characteristics of social media}

Real estate companies say that the use of the Internet has changed a lot of consumer behavior because the consumers now spend most of their time surfing the Internet. Traditional marketing methods and even its concepts have been influenced by the use of social media (i.e., creating a new environment/market in these media). Social media are easy to use, low cost, almost free, and capable of making an impact. Through this media, companies have been able to communicate with others and have facilitated the access and circulation of information to consumers.

"We have given the Social media a great deal of attention. We have included it in our communication and marketing strategy. When we launch an advertising campaign for our properties, we publish news about them in these media, so that they will be documented as part of our news, events, and announcements. "(H.H.) Companies have been able to identify their reputation through social media. The Internet has helped reach far and wide audiences, attracting foreigners and Gulf investor to invest in Bahrain and creating a dynamic real estate market. Instagram has a high speed of penetration and a significant impact on consumers because of its ease of use on various smart devices. Employment of social media in marketing strategy. Bahraini real estate companies use Instagram to publish photos, videos, and news, and show the stages of development of projects and deals, in addition to responding to customer inquiries. Some companies define how each medium of social media can be used: LinkedIn to market jobs at the company; Instagram and Facebook to showcase projects, communicate with consumers, document articles and news; and YouTube to showcase projects and interviews, and connect the user to the project by tagging.

Some Bahraini real estate companies have used traditional media to promote modern media, such as displaying account names in newspaper advertisements. Some Bahraini real estate companies consider that their presence in Social media enhances social responsibility at the internal level, providing information and increasing content on the site to reach external investors.

"Through the use of social media, we aim to raise awareness among the public about the size, importance, and credibility of our company. The company is also trying to target the largest proportion of potential customers from outside Bahrain. Therefore, the objective is to promote social responsibility internally and to provide information and content through these media to reach investors abroad. For example, our company organizes many competitions and events to make the company continuously visible, even if the public is not interested in real estate at present." (B.F.)

"We are interested in increasing the number of followers because they are our real capital. We understand that the number of followers has now become a kind of trade; many accounts collect their followers to make profits from their advertisers. The greater the number of followers of the company's accounts, the more successful the projects will become. As our brand has become a strong brand in real estate development, our goal is to support this brand to the consumer through social media, and a way of introducing people to our products." (R. O). Some real estate companies emphasize the role of the consumer in changing the strategic marketing plan. The consumers determine which channel they wish to use to communicate with the company. Bahraini real estate companies believe that social media plays a major role in attracting consumers. However, some companies have difficulties in imposing themselves on these media and, therefore, cannot influence potential customers.

\section{Social media and corporate reputation}

Bahraini real estate companies agree that social media are credible only if the message is also published in the company's accounts. This is because the information published in these accounts is 
accurate and credible. However, if real estate companies rely on real estate brokers, it could result in a negative impact that would harm the company's reputation.

"You cannot verify the authenticity of the sender's source in the social media. For example, you receive a message about a building for sale, but you cannot predict whether it is real or fake and whether the sender has sufficient credibility, so we use only the press." (A.W.)

"Not everything that is published, exchanged, or shared in the social media is true, and it may be $70 \%$ false. Moreover, this could affect the reputation of the company."(B.A.)"We have gone through the financial crisis; there are buildings that have not been completed and others that have been late in delivery. The investor is concerned about his investments and must be reassured. Social media is only supportive of the traditional media in improving our reputation "(B.F.)

Seven real estate companies agree that there is no negative impact on the use of social media in communication and marketing because their use enhances the marketing plan, the market position, and the relationship with the consumer. Three companies pointed out that social media had a negative impact, especially on the credibility of the message. Negative comments in these media are not deleted in respect of consumer opinion, which affects the image and reputation of the company.

\section{Discussion}

Bahraini real estate companies are interested in the emergence of their personality in the Social Networking Sites by highlighting their mission, goals, and values in accordance with the laws in force in the Kingdom of Bahrain. The Bahraini real estate companies have confirmed their commitment to credibility in dealing with consumers, and this is reflected in their values and culture. Companies are also interested in creating a corporate image and ensuring their continuous presence on social networking sites. These companies seek to identify potential audiences and target groups.

Thus, the company's personality appears in the way it presents itself to customers and stakeholders; this is what distinguishes it from others (Balmer, 2001; Van Riel \& Balmer, 1997). This trend is consistent with what Helen Stuart (1999) referred to in the corporate identity management model when she confirmed that the identity of the company is a representation of her personality. This is a clear description of the fundamentals that any company must rely on since its inception. This is naturally reflected in content sent through social media. Bahraini real estate companies have paid attention to social networking. However, this concern varies from company to company depending on how these media are used in communication and marketing strategies. The companies design the project to be marketed, determine the target audience, and adjust the budget, and then determine the optimal marketing medium. On the traditional media level, Bahraini real estate companies have agreed to use the newspapers extensively to promote marketing activities to reach the target groups and considered them the first intermediary to market their products. Bahraini real estate companies are in line with many studies that have confirmed the importance of traditional media in building corporate image and reputation management (Kotler \& Keller, 2012; Kaplan \& Haenlein, 2010; Kaplan, 2015). Real estate companies praised the characteristics of social media and its role in building a corporate image of the company through its projects and its ability to attract the public. Some real estate companies stressed the need to use traditional media together with new media because they complement each other; traditional media are no longer sufficient for communication and marketing.

The Mangold and Faulds model focus on the characteristics and good use of social media for the benefit of the organization. The interviews revealed that the use of the Internet has changed the behavior of consumers, and the marketing methods of products and services, as it created a new marketing environment in these media. This is because these media have distinctive characteristics (Cornelissen, \& Elving, 2003). It has also demonstrated its ability to know users' views about products and services, making consumers trust each other's experience and potentially make purchasing decisions based on these experiences. At the same time, these media enabled companies to know their reputation and access various internal and external audience, while the consumer has become more communicative and interactive with companies in contrast to traditional means. The recommendations made by the Mangold and Faulds model support this approach. The authors argue that managers should adapt to the new form of communication and take advantage of the power of consumer chatter in these ways and amplify them to influence other consumers. 


\section{Limitations and Scope for Future Research}

The present study used the qualitative approach (in-depth interviews as a research tool) to find out the trends of real estate companies on the use of social media in marketing strategies for their services and to communicate with stakeholders. However, future research could be geared towards using a quantitative approach in order to measure the impact of integrating social media and mobile marketing into corporate marketing strategy. Such an approach should lead to significant results in measuring the extent of the use of social media in predicting consumer behavior.

\section{References}

Balmer J. M.T. (2001). Corporate identity, corporate branding and corporate marketing seeing through the fog. European Journal of Marketing 35(3/4): 248-291.

Barnett M., Jermier J. \& Lafferty B. (2006). Corporate Reputation: The Definitional Landscape, Corporate Reputation Review, Volume 9, Number 1. PP. 28-38.

Berger, A. A., (2011). Media and Communication Research Methods: An Introduction to Qualitative and Quantitative Approaches. 2nd Edition, p. 138.

Cornelissen, J. P. \& Elving, J.L. (2003). Managing corporate identity: an integrative framework of dimensions and determinants. Corporate Communications: An International Journal 8(2): 115.

Doorley J. \& Garcia H. (2011). Reputation Management the Key to Success Public Relations and Corporate Communication. New York, Routledge, Second Edition, p. 22-114

Floreddu, P. B. (2014). Managing online reputation: the role of social media, Department of Economics and Business, University of Cagliari, Francesca Cabiddu, PhD, p. 1-23. Retrieved from

http://www.marketingtrendscongress.com/archives/2013/pages/PDF/673.pdf.

Gillin, P. (2007). The new influencers: A marketer's guide to the new social media. Sanger, CA: Quill Driver Books http://journal.transformativeworks.org/index.php/twc/article/view/35/48 Retrieved 30/11/2019

Goodrich, K. \& De Mooij, M. (2014). How 'social' are social media? A cross-cultural comparison of online and offline purchase decision influences. Journal of Marketing Communications 20(1-2): 103-116.

Kaplan, A. (2015). Social Media, the Digital Revolution, and the Business of Media. International Journal on Media Management 17(4): 197-199.

Kaplan, A.M. \& Haenlein, M. (2010). Users of the world, unite! The challenges and opportunities of social media. Business Horizons 53; 59-68. Retrieved from

http://www.sciencedirect.com/science/article/pii/S0007681309001232.

Kotler, P. \& Keller, K.L. (2012). Marketing Management. New Jersey, USA: Pearson Education. P. 475-476.

Lindlof, T. R.; \& Taylor, B. C. (2011). Qualitative Communication Research Methods. 3rd Ed. USA: Sage. p. 8.

Mangold, W. \& Faulds, D. (2009). Social media: The new hybrid element of the promotion mix. Business Horizons 52: 357-365. Retrieved from

http://www.sciencedirect.com/science/article/pii/S0007681309000329 23-10-2015 01:15am.

Melewar, T.C. (2008). Facets of Corporate Identity, Communication and Reputation. Routledge, New York.

Olins, O. (2014). Brand New: The Shape of Brands to Come. Thames \& Hudson: London.

Stuart, H. (1999). Towards a definitive model of the corporate identity management process, Corporate Communications: An International Journal 4(4): 200-207.

Van Riel, C.B.M. \& Fombrun C. J. (2007). Essentials of Corporate Communication: Implementing Practices for Effective Reputation Management. Routledge: London.

Van Riel, B.M. \& Balmer, J. M.T. (1997). Corporate identity : the concept, its measurement and management. European Journal of Marketing 31(5/6) : 55-342.

Vollmer, C. \& Precourt, G. (2008). Always On : Advertising, Marketing, and Media in an Era of Consumer Control. McGraw Hill : USA.

Zarrella, D. (2010). The Social media Marketing Book, O'Reilly Media: Canada. 